\title{
Memória, identidade e digitalização de bens culturais: o legado da Missão de Pesquisas Folclóricas no Brasil
}

\author{
Urbano Lemos Jr. \\ Doutorando; Universidade Anhembi Morumbi, São Paulo, SP, Brasil; \\ urbano.lemos@hotmail.com \\ Vicente Gosciola \\ Doutor; Universidade Anhembi Morumbi, São Paulo, SP, Brasil; \\ vicente.gosciola@gmail.com
}

Resumo: O artigo recupera uma iniciativa inédita e visionária. Em 1938, Mário de Andrade constata a necessidade de registrar manifestações culturais populares sob o risco de desaparecerem com a crescente urbanização do país e envia uma equipe ao Norte e Nordeste do Brasil para a Missão de Pesquisas Folclóricas. O grupo reúne um legado por meio de registros sonoros e audiovisuais. Passados mais de sessenta anos, o material foi digitalizado e hoje é um dos mais importantes registros culturais brasileiros. O estudo aponta essa diligência como percursora em busca de uma consciência preservacionista em solo brasileiro, já que preconiza a importância do registro de materiais sobre patrimônios culturais e sua enorme relevância para a preservação de memórias e identidades. Deste modo, o objetivo do artigo é alumbrar sobre os novos procedimentos de conservação, divulgação e difusão de bens culturais na contemporaneidade. A metodologia empregada é analisar tanto a formatação de um produto físico com materiais digitalizados quanto o desenvolvimento de uma plataforma web com possibilidades significativas para a preservação e difusão de bens culturais. O estudo recorre a teoria da modernidade tardia para dissertar sobre o caráter de continuidade de tradições que são reincorporadas e reinventadas no ciberespaço. Os resultados da pesquisa buscam ampliar o debate sobre a importância da digitalização de documentos sobre patrimônios culturais e sua consequente preservação. Conclui-se, portanto, que a digitalização pode tornar-se um repositório capaz de conservar e difundir os valores culturais de um patrimônio, contribuindo com a preservação de memórias e a formação de identidades.

Palavras-chave: Patrimônio. Digitalização. Memória. Identidade Cultural. Missão de Pesquisas Folclóricas. 


\section{Introdução}

Para darmos início à discussão sobre a importância da preservação de memórias na contemporaneidade é importante recuperarmos acontecimentos recentes que sinalizam uma atenção ao patrimônio cultural brasileiro. Em setembro de 2018, um incêndio de grandes proporções no Museu Nacional, no Rio de Janeiro, nos alertou para a importância de preservar e, de alguma forma, resguardar o patrimônio cultural. $\mathrm{O}$ museu, vinculado à Universidade Federal do Rio de Janeiro (UFRJ), era o mais antigo em atividade no Brasil, sendo fundado por Dom João VI em 1818 sob a denominação de Museu Real.

A maior parte do acervo, aproximadamente 20 milhões de itens, foi totalmente destruída pelo incêndio. No espaço haviam itens relacionados às áreas de Antropologia, Botânica, Entomologia, Geologia e Paleontologia ainda dos primeiros anos do País. Fósseis, múmias, registros históricos e obras de arte viraram cinzas de uma hora para outra na instituição que recentemente completara 200 anos. Uma perda incalculável do ponto de vista cultural. De acordo com uma reportagem do jornal O Estado de S. Paulo, o incêndio reforça a necessidade de digitalizar acervos históricos, “[...] tanto para fins de pesquisa quanto de preservação das informações - e até mesmo, dos próprios artefatos, em versão virtual” (ESCOBAR, 2018, não paginada).

Por outro lado, também lembramos que há mais de 80 anos um grupo de pesquisadores deu início a um dos projetos preservacionistas mais importantes no Brasil: a Missão de Pesquisas Folclóricas. Em 1938, Mário de Andrade verifica a necessidade de registrar as manifestações populares sob o risco de desaparecer com a crescente urbanização do país. A expedição visitou dezoito cidades na Paraíba, cinco em Pernambuco, duas no Piauí, uma no Maranhão, uma no Ceará e uma no Pará. A equipe composta por quatro pesquisadores

[...] registrou em discos, fotografou, filmou e anotou em cadernetas de campo as manifestações populares encontradas nessas regiões. Além disso, anotou versos da poética popular, dados sobre arquitetura e recebeu centenas de objetos etnográficos. (AZEVEDO, 2000, p. 13) 
Esse material ficou por muitos anos sem o conhecimento do público: "Decorridos mais de sessenta anos após essas expedições a coleção foi sendo organizada, tombada e restaurada, tendo seu catálogo publicado" (AZEVEDO, 2000, p. 10). O material coletado foi estruturado durante quinze anos por Oneyda Alvarenga, ex-diretora da Discoteca Pública Municipal, que também organizou o fichário folclórico.

O resultado desse trabalho foi o legado de uma coleção "[...] composta por 1.500 melodias, 1.126 fotografias, 17.936 documentos textuais, 19 filmes de 16 e 35mm, 800 peças catalogadas e 258 não catalogadas de objetos folclóricos” (BOLSONI, 2000, p. 15). As cadernetas de campo foram catalogadas como documentos textuais. Foram mais de 20 cadernetas e um total de 3.878 páginas com anotações e desenhos dos pesquisadores durante os seis meses da Missão de Pesquisas Folclóricas.

Em virtude do que foi mencionado, o artigo se debruça em compreender as novas possibilidades preservacionistas na contemporaneidade. $\mathrm{O}$ objetivo da pesquisa é ampliar o debate sobre as metodologias de preservação e conservação de bens culturais nos espaços virtuais. Para tanto, a metodologia empregada é endossada com a análise da digitalização das cadernetas de campo, disponibilizadas em DVD, além de explorar o desenvolvimento de um site com parte dos registros da Missão de Pesquisas Folclóricas. A pesquisa recorre ainda aos escritos de Caroline Kraus Luvizotto que, a partir da modernidade tardia, considera as potencialidades apresentadas pelas tecnologias informacionais e comunicacionais para a disseminação da tradição e preservação da memória coletiva na atualidade. Para ela, “[...] a tradição deve ser considerada dinâmica, e não estática, uma orientação para o passado e uma maneira de organizar o mundo para o tempo futuro" (LUVIZOTTO, 2010, p. 64).

Os resultados do estudo servem como arcabouço para ampliar a discussão sobre a importância da digitalização de materiais sobre patrimônios culturais na contemporaneidade. A justificativa principal da pesquisa é que ao analisar a formatação de projetos digitalizados sobre patrimônios imateriais brasileiros também se investiga como se processam as práticas culturais de um determinado grupo social que coexistem na contemporaneidade marcadas pela 
interculturalidade, hibridez e pluralidade. À vista disso, a pesquisa depreende que digitalização pode contribuir com a memória social, a identidade e o multiculturalismo brasileiro. Em suma, a digitalização de bens culturais pode fortalecer e ampliar os conhecimentos sobre culturas tradicionais, além de conferir potencialidades na conservação, divulgação e difusão de bens culturais brasileiros.

\section{Em busca de uma identidade brasileira: do movimento modernista à criação de um instituto}

A manifestação mais legítima do nacionalismo artístico se dá quando esse nacionalismo é inconsciente de si mesmo. Mário de Andrade, 1928

Desde a década de 1910, as discussões sobre a identidade brasileira passaram a ser debatidas com maior afinco por intelectuais e artistas. As particularidades culturais de cada região do país passaram a ser debatidas a fim de entender o mais genuíno em cada manifestação popular. Ao refazer o percurso com os primeiros registros sobre o patrimônio nacional, encontra-se no escritor Alceu Amoroso Lima as primeiras inquietudes. No ano de 1916, Amoroso Lima e o advogado Rodrigo Melo Franco de Andrade viajam à Minas Gerais e anunciam a necessidade de preservação do passado arquitetônico. Lima publica na Revista do Brasil o artigo Pelo Passado Nacional (1916) que, segundo "estudos da professora Maria Cecília Londres da Fonseca", é "[...] a primeira alusão à cidade de Ouro Preto como relíquia nacional" (FONSECA, 1997 ${ }^{1}$ apud MAGALHÃES, 2001, p. 191). No artigo, Amoroso Lima enfatiza que somos responsáveis pelo nosso passado, “[...] mas não poderemos levar adiante a nossa missão se desprezarmos o que nos constitui o passado da pátria”. O autor conclama ainda que a "[...] perspectiva das origens é um elemento primordial dos povos em formação, é pela memória que deve começar a obra de construção nacional" (LIMA, $1916^{2}$ apud LUCA, 1999, p. 89).

De acordo com Oliveira, já em 1919, o escritor Mário de Andrade realiza a "[...] coleta de composições populares no interior paulista e em viagens às cidades históricas de Minas Gerais [...]” (OLIVEIRA, 2011, p. 105). Delas resultarão as conferências que compõem a obra $A$ arte religiosa no Brasil $^{3}$ 
(1920), na qual “[...] o autor já demonstra uma preocupação na preservação do patrimônio cultural, especialmente o arquitetônico" (OLIVEIRA, 2011, p. 105). Para Mário de Andrade:

[...] após as primeiras décadas da febre aurífera [...] pôde a Igreja reinar com mais autoridade e liberdade, bem como implantar um estilo arquitetônico original, próprio, de acordo com suas condições materiais e técnicas. (ANDRADE, $1993^{4}$ apud NATAL, 2007, p. 198)

A preocupação com o patrimônio brasileiro e a necessidade de “[...] conhecer as origens de uma tradição nativa" (OLIVEIRA, 2011, p. 105) ganharam força a partir das mensagens nacionalistas emitidas pelo movimento modernista $^{5}$ e, posteriormente, pela Caravana Modernista (1924), comandada por Mário de Andrade que retorna ao estado de Minas Gerais "ciceroneando um grupo de intelectuais".

Faziam parte da caravana: Oswald de Andrade, seu filho Nonê, Tarsila do Amaral, o jornalista René Thiollier, a fazendeira Olívia Guedes Penteado, o advogado Goffredo Telles e o poeta francosuíço Blaise Cendrars. Oswald batizou a excursão de Viagem de descoberta do Brasil, numa clara referência aos bandeirantes paulistas do século XVII, os quais chefiaram as primeiras expedições ao então ignoto território. A viagem dos modernistas objetivava "conhecer" as origens de uma tradição nativa a partir da qual se deveria sustentar a inovação estética por eles almejada. (NATAL, 2016, p. 169)

Os vanguardistas viram no barroco mineiro um símbolo valioso do passado. O escritor Mário de Andrade se posiciona com preocupação em conhecer as raízes culturais brasileiras. $\mathrm{O}$ escritor se interessa em apreender os processos “[...] de constituição e reinvenção dos elementos que compõem a memória coletiva informadores de nossas matrizes europeias, africanas e ameríndias" (NOGUEIRA, 2007, p. 258).

Entre os anos de 1928 e 1929, Mário de Andrade realiza ainda uma expedição etnográfica ao Nordeste do país e passa a evidenciar em seus trabalhos as diversas manifestações culturais brasileiras. O escritor viaja desacompanhado e chama a expedição de "viagem etnográfica". Segundo José Tavares Correia de Lira: 
[...] a imagem eleita para descrever o que vira pelo Nordeste certamente repercute o estágio de campo desta viagem etnográfica feita com total disponibilidade e pouco método, de colheita paciente e sem preconceitos. (LIRA, 2005, p. 143)

Cabe destacar que, em agosto de 1927, o escritor paulista desembarca na Amazônia a "convite da milionária Olívia Guedes Penteado" com a ideia de “[...] reescrever o Macunaíma, iniciado em fins de 1926”, destaca Lira (2005, p. 146). O livro é publicado em 1928 e é considerado um dos principais romances modernistas por retratar as características do povo brasileiro a partir de histórias das tradições indígenas do norte da Amazônia.

Além da literatura, o escritor "[...] traça um caminho de pesquisa sistemática da composição artística, ligado desde cedo a sua atuação como jovem professor do Conservatório de Música de São Paulo" (OLIVEIRA, 2011, p. 107). Mário de Andrade mostra interesse tanto na pesquisa quanto no registro das manifestações culturais presentes nos ritmos, nas melodias e na instrumentação. Em consequência, publica o livro Ensaio Sobre a Música Brasileira (1928), que, segundo Flávia Camargo Toni (1990), teria o objetivo de sintetizar uma estética da música nacional. Desse modo:

[...] amadurece o musicólogo e conhecedor do cantar popular do Brasil e revigora a crença na necessidade do registro das manifestações que o progresso coloca em risco de desaparecimento, gravando, fotografando e filmando. (TONI, 2008, p. 26)

O historiador Caion Natal diz que o modernismo marioandradino surge enquanto meio de reconhecimento do universo sociocultural brasileiro em que “[...] o fator ideológico já estava embutido no âmbito estético e que ambos figuravam simultaneamente no pensamento de Mário de Andrade" (NATAL, 2016, p. 164). Segundo o autor, o pensamento do poeta não se limitava à literatura, mas "compreendia o anseio maior de interpretar a identidade da nação" (NATAL, 2016, p. 164).

Por conta da aproximação com Minas Gerais e com as culturas brasileiras, o escritor paulista torna-se conselheiro do jovem mineiro Carlos Drummond de Andrade que, assim como ele, voltava seus interesses para ideias sobre nacionalismo, alteridade e arte. A recorrência de assuntos na poesia de 
ambos se desdobra em temas que versam sobre cultura e conhecimentos populares. Os dois escritores trocam inúmeras cartas e, em uma delas, Carlos Drummond de Andrade fala ${ }^{6}$ da falta de informações sobre o patrimônio arquitetônico mineiro:

Estou positivamente desolado com o que acaba de suceder. Você me pede fotografias, datas de construção e mais informes sobre igrejas mineiras e eu lhe contesto com quase nada, pois quase nada me arranjaram. O resultado da pesquisa é desolador: Acabei verificando que não havia nada, e que a tradição em Minas é uma blague (como eu já suspeitava, aliás). (ANDRADE, 2003, p. 341-342)

É importante lembrar que, desde 1929, Drummond ocupava uma posição proeminente como funcionário público em órgãos mineiros e, posteriormente, como auxiliar de gabinete da Secretaria do Interior de Minas, o que contribuiu para sua formação modernista e também nas primeiras empreitadas a serviço do patrimônio brasileiro. A Secretaria era dirigida por Gustavo Capanema, um antigo amigo do poeta de Itabira.

Em 1934, Capanema é nomeado pelo presidente Getúlio Vargas para ocupar a pasta do Ministério da Educação e Saúde e passa a reunir um grupo de alto nível, articulando um sistema que envolvia os campos da educação, da música e do patrimônio histórico e artístico. Já em São Paulo:

\footnotetext{
Fábio Prado assumiu a prefeitura de São Paulo e seguindo as tendências do governo federal, convidou Paulo Duarte para apresentar um projeto para o Departamento de Cultura do município. (GONSALES, 2013, p. 55)
}

A consolidação de uma Secretaria de Cultura era um projeto antigo de Mário de Andrade que, ao lado de um grupo de amigos, se reuniam para discutir "[...] cultura, identidade brasileira e preservação do patrimônio histórico brasileiro", lembra Gonsales (2013, p. 56). Nesse período, Mário de Andrade é convidado para ser o diretor do Departamento de Cultura do município de São Paulo (1935-1938) e logo passa a apresentar diversas propostas com o “[...] conceito de arte patrimonial" (NOGUEIRA, 2007, p. 257).

No ano de 1936, Mário de Andrade foi solicitado a preparar um projeto para a criação de uma instituição nacional de proteção do patrimônio. Esse documento foi usado nas discussões preliminares sobre a estrutura e os objetivos 
do Serviço de Patrimônio Histórico e Artístico Nacional (SPHAN), criado por decreto presidencial assinado em 30 de novembro de 1937. O novo órgão passa a realizar o tombamento de patrimônios materiais brasileiros. O Conjunto Arquitetônico e Urbanístico da Cidade de Ouro Preto é um dos primeiros a ser reconhecido como patrimônio nacional, tombado em 20 de janeiro de 1938 . Nesse mesmo ano, a instituição realiza o tombamento arquitetônico e urbanístico de 234 bens, em 10 estados, dentre eles, os conjuntos arquitetônicos e urbanísticos das cidades mineiras de Diamantina, Mariana, São João del-Rei, Serro e Tiradentes.

O patrimônio arquitetônico passa a ocupar lugar de destaque em políticas preservacionistas, nesse ínterim, Mário de Andrade mostra preocupação também com o patrimônio cultural, presente nos saberes e fazeres das comunidades tradicionais, constitutivos da cultura e identidade nacional. Nesse sentido, o escritor adverte que "[...] a maior conquista das artes contemporâneas está em reencarnar a inteligência dentro do compromisso constante da entidade humana, coisa rara mesmo nos maiores gênios do passado" (ANDRADE, 1984, p. 359).

Nessa mesma época, o tema Folclore e Educação alcança relevância na ocasião do Congresso Internacional de Folclore, realizado em 1936, em Paris. Segundo Luiza Angélica Paschoeto Guimarães (2012), o tema Folclore passou a ser visto com atenção por pesquisadores por conta das relações com diversas áreas do conhecimento, tais como, Antropologia e História, além das possibilidades de penetração no campo do ensino.

Já no Brasil é no ano de 1938 que Mário de Andrade empreende uma das mais importantes expedições culturais brasileiras. O escritor promove a Missão de Pesquisas Folclóricas enviando ao:

[...] Norte e ao Nordeste do país uma equipe de pesquisadores que, de fevereiro a julho de 1938, fez gravações de música popular de tradição oral in loco em diversos pontos de Pernambuco, Paraíba, Maranhão e Pará. (SANDRONI, 2008, p. 275)

Essa foi a primeira documentação sobre o folclore brasileiro realizada em diferentes estados. A equipe era composta pelo arquiteto Luís Saia, que era o chefe da expedição; pelo músico e maestro Martin Braunwieser, pelo técnico de 
gravação Benedicto Pacheco e pelo auxiliar geral Antonio Ladeira. Eles “[...] estavam preparados para gravar, filmar e fotografar as manifestações musicais" que encontrassem, ressalta Toni (2008, p. 29).

Nos dias em que não gravava ou filmava manifestações musicais, a Missão de Pesquisas Folclóricas dedicava-se a outros temas e pelas cadernetas de campo que, no final da viagem, somaram 3.878 páginas manuscritas, percebe-se que tais apontamentos eram feitos principalmente pelo chefe do grupo. Os dados registrados revelam os interesses do autor em escultura e técnicas de fabrico de vários utensílios populares. (TONI, 2008, p. 32-33)

Figura 1 - Pesquisa oral e fotográfica sobre o Bumba-meu-boi em Belém, Pará

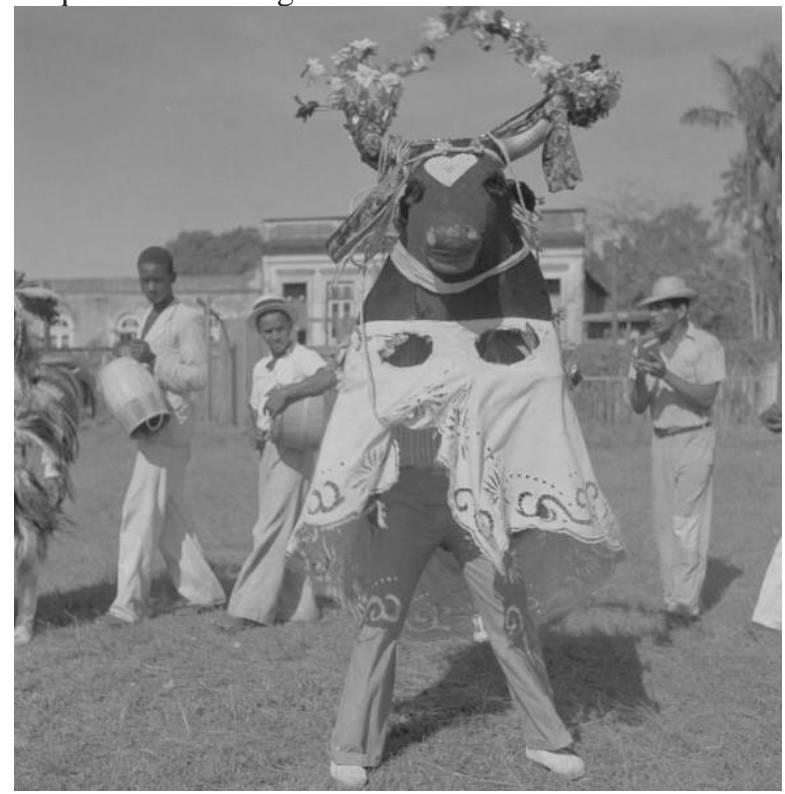

Fonte: Cerqueira; Nascimento (2010).

Os pesquisadores buscavam registrar na íntegra os formadores da cultura brasileira. Ângela Prysthon nos lembra que a modernização tecnológica se apresenta para os modernistas como um conjunto inédito, possibilitando novas maneiras de organizar o discurso (seja visual, sonoro ou verbal) (PRYATHON, 2002). Segundo a autora, esse “[...] repertório, associado ao reprocessamento das origens indígenas e africanas do brasileiro, forma a base de urna estética nova, de urna profunda reestruturação na cultura brasileira" (PRYSTHON, 2002, p. 147).

Mário de Andrade estava em busca de registrar e, de certa forma, salvaguardar a gênese da nossa identidade brasileira. Desde as primeiras incursões do movimento modernista, até a criação de um instituto para debater e 
proteger o patrimônio material brasileiro constata-se uma preocupação não apenas com a documentação, mas, também, com a difusão e a preservação das nossas raízes, um empenho em apreender saberes e fazeres brasileiros.

\section{Dos registros culturais às possibilidades para preservação e difusão de bens culturais na contemporaneidade}

Faz-se necessário e cada vez mais que conheçamos o Brasil. Que sobretudo conheçamos a gente do Brasil. Mário de Andrade, 1936

Por muitos anos, os registros realizados pela equipe da Missão de Pesquisas Folclóricas não foram divulgados. Foi somente em 1990 que os registros foram digitalizados e “[...] José Saia Neto encarregou-se de decifrar as cadernetas utilizadas por seu pai, Luís Saia e os outros membros da missão" (GONSALES, 2013, p. 64).

Em 2006, o SESC lança uma coletânea com parte do material reeditado em seis discos e um livro com textos de pesquisadores e colaboradores do projeto. O material digitalizado contém fonogramas de manifestações culturais como acalantos, aboios, cantos com viola, coco, xangô, bumba-meu-boi, entre outras.

Mas foi em 2010, setenta e dois anos após a expedição, que o material foi reconhecido pelo Conselho Consultivo do IPHAN e aprovado em um financiamento para recuperar os registros produzidos na Missão de Pesquisa Folclórica. A iniciativa assistida pela Caixa Econômica Federal disponibilizou um livro e um DVD com parte do conteúdo das cadernetas de campo, além de contar com gravações de áudios e fotos digitalizadas.

O projeto de digitalização das cadernetas foi coordenado pela socióloga Vera Lúcia Cardim Cerqueira. Segundo a pesquisadora, essa ação deu visibilidade aos registros realizados pela Missão de Pesquisas Folclóricas, “[...] gerando, portanto, uma demanda pela consulta do material e seu uso em exposições externas e em publicações e estudos de diversas áreas do conhecimento" (CERQUEIRA, 2016, p. 148). 
O material foi publicado em DVD e contempla a digitalização de 642 fotografias, 92 áudios, 30 recortes de jornais da época, 21 cadernetas de campo, 21 minidocumentários, além de correspondências e documentos. O material original permanece como parte do Acervo Histórico da Discoteca Oneyda Alvarenga armazenado no Centro Cultural São Paulo (CCSP). Cerqueira lembra ainda que o material coletado pela Missão de Pesquisas Folclóricas foi redescoberto e, setenta anos depois "de a equipe de pesquisadores ter realizado os trabalhos" (CERQUEIRA, 2016, p. 127), foi inscrito no livro de Tombo Histórico do Iphan, em fevereiro de 2008.

Figura 2 - Caderneta de campo digitalizada mostra Caboclinhos em Itabaiana, Paraíba

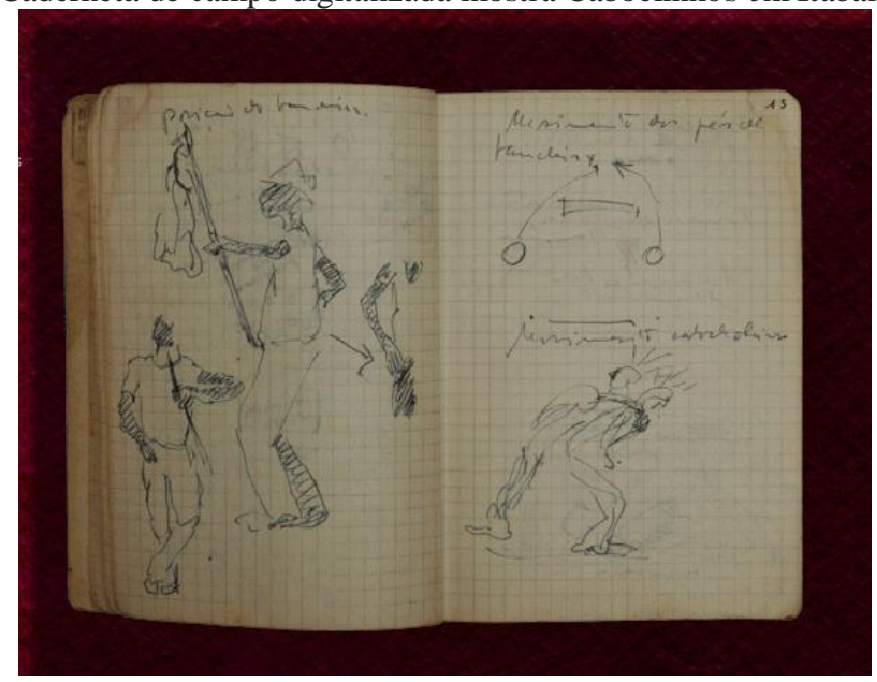

Fonte: Cerqueira; Nascimento (2010).

Figura 3 - Registro fotográfico dos Caboclinhos em Itabaiana, Paraíba

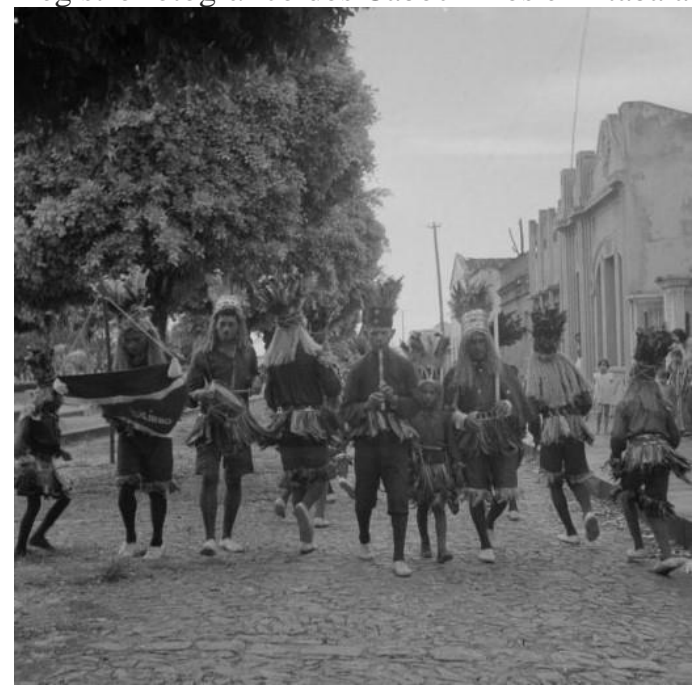

Fonte: Cerqueira; Nascimento (2010). 
A importância da digitalização é tamanha que parte do acervo também está disponível em uma homepage $e^{7}$ que apresenta o projeto, traz informações técnicas da Missão de Pesquisas Folclóricas e reúne fotografias, vídeos, documentos e quatro cadernetas de campo. A barra de navegação situada na parte inferior da tela representa as capas de cada caderneta, de acordo com a ordem estabelecida pelos pesquisadores da Missão. O menu superior contém as demais opções de navegação e conteúdo do projeto multimídia com as abas: Texto, Audiovisual e Cadernetas.

Figura 4 - Abertura do site com a foto dos quatro pesquisadores

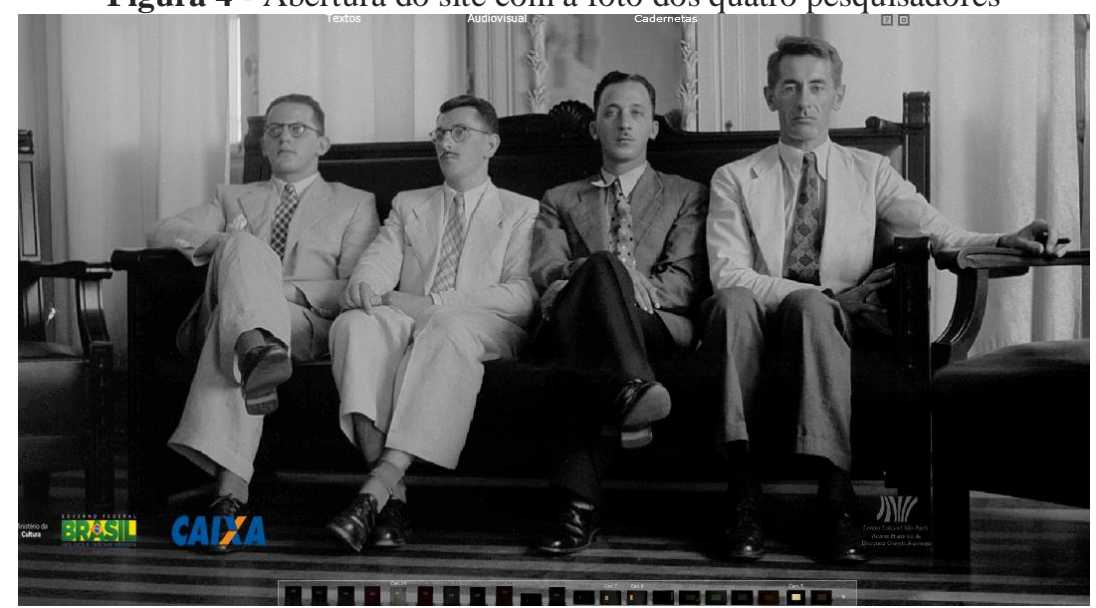

Fonte: Cerqueira; Nascimento (2010).

Conforme retratado, a Missão de Pesquisas Folclóricas teve como enfoque o mapeamento “[...] sob a mira da preservação de um patrimônio cambiante, a ser radiografado de tanto em tanto para pesquisas de toda ordem" (TONI, 2008, p. 26). Deste modo, verifica-se que tanto a formatação de um produto físico quanto o desenvolvimento de uma página web são possibilidades significativas para a preservação e a difusão de bens culturais na contemporaneidade. Tais projetos auxiliam na busca de uma consciência preservacionista a fim de compreender e salvaguardar a diversidade cultural brasileira. Atualmente, esse patrimônio cambiante requer, além da investigação, identificação e interpretação, ferramentas que auxiliem na difusão e, consecutiva preservação. 
À luz da teoria da modernidade tardia a pergunta que surge é como fazer o registro de memórias e manifestações culturais na atualidade? De acordo com Luvizotto, “[...] a modernidade tardia indica uma mudança no modo de vivenciar as relações a partir da identificação da razão como o elemento ordenador" (LUVIZOTTO, 2013, p. 253) e é fundamental rever e atualizar as práticas para a preservação das memórias coletivas de um determinado grupo social. Pode-se dizer que a preservação de patrimônios culturais passa a ser instituída em novos meios e com a tecnologia como pano de fundo para a construção de linguagens midiáticas e novos formatos.

Segundo a pesquisadora, por meio da digitalização e da inserção de conteúdos em ambientes virtuais "[...] é possível criar, inventar, reinventar tradições, conferindo-lhes a aparência de repetição e preservando a memória coletiva” (LUVIZOTTO, 2015, p. 25). A pesquisadora ainda destaca que a infraestrutura de conectividade da internet facilita a comunicação no processo de difusão de elementos da tradição, "[...] objetivando manter vivo aquilo que se apresenta como origem de um povo em seus aspectos culturais e históricos" (LUVIZOTTO, 2015, p. 25).

Já o sociólogo Anthony Giddens, ressalta que a modernidade tardia é uma espécie de revigoramento do passado por meio da reflexividade e interpretação do mundo contemporâneo. Segundo o autor:

[...] vivemos de modo muito mais reflexivo do que as gerações passadas. [...] A radicalização da modernidade significa ser obrigado a viver de modo mais reflexivo, enfrentando um futuro mais incerto e problemático. (GIDDENS, 2000, p. 87)

Neste sentido, a criação de uma plataforma web e a digitalização de materiais sobre patrimônios culturais proporcionam ao usuário a escolha de novos caminhos para obter novas experiências e, assim, consolidar novos conhecimentos. Constata-se, portanto, desmedida relevância científica e preservacionista já que busca explorar as potencialidades da tecnologia e sua contribuição com a preservação de saberes e expressões de uma determinada comunidade. Conforme salienta Arantes: 
[...] por essa razão destaca-se hoje, uma vez mais, a urgência sempre evocada pelos pesquisadores, de registrarem e conservarem o patrimônio [...] como que numa tentativa de fixar no tempo as artes e ofícios difusamente desenvolvidos pelo engenho humano. (ARANTES, 2004, p. 16-17)

Desta forma, a formatação de projetos sobre patrimônios brasileiros exigem ponderar sobre as potencialidades da digitalização de saberes, fazeres e expressões culturais que poderiam se perder com o tempo. A digitalização e o desenvolvimento de uma plataforma web endossam a importância de movimentos contemporâneos que dialoguem com o passado, vislumbrando um futuro que proteja as memórias e os saberes do seu povo.

\section{A noção de bem cultural, a criação do Iphan e a salvaguarda de memórias na contemporaneidade}

Alguém deve rever, escrever e assinar os autos do Passado antes que o Tempo passe tudo a raso. Cora Coralina, 1985

Antes de falarmos sobre a criação do Iphan faz-se necessário dissertarmos sobre a ideia de cultura. Para perquirir sobre a noção de bem cultural, Maria Tarcila Ferreira Guedes e Luciana Mourão Maio (2016) citam a Conferência de Haia, em 1907, que estabelecia regras internacionais para a conduta de guerra. Os regulamentos de proteção de edificações religiosas, artísticas e cientificas serviram de alicerce para a elaboração da Convenção para a Proteção de Bens Culturais em Caso de Conflito Armado, em 1954. Segundo as Convenções Internacionais, o bem cultural é "entendido como aquele bem que deve ser protegido, em virtude de seu valor e de sua representatividade para determinada sociedade" (GUEDES; MAIO, 2016, não paginada). Já Flávio Carsalade destaca que:

[...]qualquer bem produzido pela cultura é, tecnicamente, um bem cultural, mas o termo, pela prática, acabou se aplicando mais àqueles bens culturais escolhidos para preservação - já que não se pode e nem se deve preservar todos os bens culturais -, fazendo com que, no jargão patrimonial - e por força de convenções internacionais -, a locução bem cultural queira se referir ao bem cultural protegido. (CARSALADE, 2016, p. 14) 
No Brasil, o conceito de bem cultural passou por transformações ao longo do tempo. De acordo com Guedes e Maio (2016), até os anos setenta, o termo era utilizado no sentido de bem protegido. No entanto, a nomenclatura é repensada a partir de 1979 por Aloísio Magalhães “[...] que inseriu a cultura no âmbito das políticas sociais" (GUEDES; MAIO, 2016). Aloísio assume a direção do IPHAN e procura resgatar ideias de Mário de Andrade sobre preservação cultural e políticas de patrimônio. Magalhães vislumbra o fomento de um arquivo da identidade brasileira por meio da criação do Centro Nacional de Referência Cultural (CNRC), em 1975.

Segundo o filosofo Álvaro Vieira Pinto (1969, p. 121-123), a cultura é uma criação do homem, "[...] resultante da complexidade crescente das operações de que esse animal se mostra capaz no trato com a natureza material, e da luta a que se vê obrigado para manter-se em vida". Trata-se de um processo social "[...] pelo qual o homem acumula as experiências", convertendo-as em ideias, que são resultados da atividade humana sobre a natureza. Segundo o autor, "[...] a cultura é um produto do existir do homem, resulta de vida concreta no mundo que habita e das condições, principalmente sociais, em que é obrigado a passar a existência" (PINTO, 1969, p. 135).

Alinhado à ideia de cultura, José Luiz de Andrade Franco ressalta que a noção de patrimônio está relacionada com "[...] aquilo que é transmitido como herança” (FRANCO, 2015, p. 164). Um processo social “[...] constitutivo de memória e da identidade", assegurando a perpetuação do patrimônio e uma "[...] vontade social de criar conexões e fortalecer a ideia de pertencimento à nação e constituição de uma identidade nacional" (FRANCO, 2015, p. 166).

Em solo brasileiro, a criação do Serviço de Patrimônio Histórico e Artístico Nacional (SPHAN), em 1937, foi uma das primeiras medidas em defesa do patrimônio visando proteger o bem cultural. O principal objetivo da instituição estava em preservar o patrimônio cultural em uma época em que o progresso já era observado como ameaça a conjuntos arquitetônicos importantes, progresso esse “[...] consubstanciado em extensas operações de modernização e embelezamento urbano, realizadas a partir do arrasamento das 
áreas mais antigas das cidades brasileiras", lembra Maria Lucia Bressan Pinheiro (2017, p. 13).

A instituição teve entre seus idealizadores um grupo de intelectuais conduzidos por Mário de Andrade e pelo advogado Rodrigo Melo Franco de Andrade. Em 1936, o ministro da Educação e Saúde, Gustavo Capanema, aprova o projeto de Mário de Andrade para criação do SPHAN. Andrade dirigia o Departamento de Cultura do município de São Paulo e indica o nome de Rodrigo Melo Franco de Andrade para a direção do Sphan. Rodrigo assume a presidência do órgão em 1937 e permanece no cargo até 1967.

A instituição é pioneira na preservação do patrimônio cultural na América Latina. Naquele momento, o objetivo estava em facilitar o acesso ao conhecimento dos bens nacionais a partir de objetos, documentos, edificações e conjuntos urbanos de valor histórico, paisagístico, artístico e arqueológico. A partir da Constituição Federal de 1988, o campo do patrimônio se amplia com a inserção da dimensão imaterial do patrimônio cultural, que passa a considerar os bens portadores de referência, ação, identidade e memória dos diferentes grupos que formam a sociedade brasileira.

O novo agrupamento configura-se como patrimônio material, patrimônio imaterial, patrimônio arqueológico e patrimônio natural. Além disso, o artigo 216 da Constituição Federal de 1988 conceitua patrimônio cultural como sendo “[...] os bens, de natureza material e imaterial, tomados individualmente ou em conjunto, portadores de referência à identidade, à ação, à memória dos diferentes grupos formadores da sociedade brasileira" (BRASIL, 1988).

Em entrevista, a historiadora Kátia Bogéa ${ }^{8}$, então presidente do Iphan, destaca a importância da Constituição de 1988 que ganhou uma nova dimensão imaterial do patrimônio reconhecendo "[...] a inclusão no patrimônio a ser preservado pelo Estado em parceria com a sociedade" (LEMOS JR; GOSCIOLA, 2018, p. 6). Segundo a pesquisadora, essa medida tirou "[...] o foco de uma história nacional única, para a ideia de diversidade cultural como base formadora da nacionalidade a partir do direito à diferença e da convivência e tolerância entre culturas distintas" (BOGÉA, 2018 apud LEMOS JR; GOSCIOLA, 2018, p. 6). 
No final da década de 1990 o órgão concretiza as propostas enunciadas na Carta Constitucional de 1988 e amplia o papel a ser desempenhado com o Registro de Bens Culturais de Natureza Imaterial. Já no ano de 2000 é criado o Programa Nacional do Patrimônio Imaterial ${ }^{9}$ (PNPI), pelo Decreto 3.551/2000 (BRASIL, 2000) com a proposta de viabilizar projetos de identificação, reconhecimento, salvaguarda e promoção da dimensão imaterial do patrimônio cultural. Instituído em quatro de agosto de 2000, o programa completa duas décadas em vigor atuando na preservação de bens culturais que expressam as identidades do povo brasileiro. Segundo o IPHAN:

[...] é um programa de fomento que busca estabelecer parcerias com instituições dos governos federal, estadual e municipal, universidades, organizações não governamentais, agências de desenvolvimento e organizações privadas ligadas à cultura e à pesquisa. (IPHAN, 2000, não paginada)

Passados vinte anos desde a implantação da Política de Salvaguarda do Patrimônio Imaterial, temas ligados à preservação e à difusão de bens culturais ainda merecem atenção. O antropólogo Antonio Augusto Arantes, que presidiu o Iphan de 2004 a 2006, destaca a importância do diálogo dos agentes de preservação "[...] com áreas de conhecimento que têm sido consideradas, até agora, menos relevantes do ponto de vista do patrimônio, como é o caso das Ciências Sociais e do audiovisual" (ARANTES, 2010, p. 53). Essa consideração nos leva a estender o diálogo de forma interdisciplinar a fim de atender a demanda acerca da preservação de patrimônios imateriais na contemporaneidade. Segundo o pesquisador:

De um ponto de vista interno à cultura e à experiência social, produto e processo são indissociáveis. As coisas feitas testemunham o modo de fazer, e o saber fazer. Elas abrigam também sentimentos, lembranças e sentidos que se formam nas relações sociais envolvidas na produção e assim, o trabalho realimenta a vida e as relações humanas. (ARANTES, 2004, p. 17)

Assim como as relações sociais realimentam a vida, conforme observa Arantes (2004), as diversas manifestações culturais também ganham força com a adoção de novas metodologias e abordagens interdisciplinares. O material coletado na Missão de Pesquisas Folclóricas, em 1938, ao ser digitalizado 
possibilita significativas abordagens sobre nossa cultura e identidade brasileira. Um legado que nos permite compreender a importância do patrimônio imaterial e da dimensão cultural que estão ligados ao espaço, tempo e representações simbólicas “[...] que os indivíduos e os grupos fazem de sua inserção na sociedade e da sociedade como um todo" (PELEGRINI, 2006, p. 62). No momento em que vivemos, o registro e as representações simbólicas são possibilidades a mais para o fortalecimento e a valorização das culturas tradicionais. Destarte, a inserção de conteúdos em ambientes virtuais pode conferir uma nova dimensão de salvaguarda do patrimônio cultural brasileiro, realimentando e reafirmando as relações sociais e a formação de identidades.

\section{Considerações finais}

Em 1936, ainda como diretor do Departamento de Cultura do município de São Paulo, Mário de Andrade já alertava para a importância de reconhecer, catalogar e salvaguardar nossa identidade cultural, responsáveis pelos nossos "caracteres raciais". Ao falar sobre a Etnografia no Brasil, o escritor diz:

[...] nós precisamos de moços pesquisadores que vão à casa recolher com seriedade e de maneira completa o que esse povo guarda e rapidamente esquece, desnorteado pelo progresso invasor. (ANDRADE, $1936^{10}$ apud CARLINI, 1993, p. 20)

Ainda hoje, passados mais de oitenta anos, o progresso invasor apontado pelo escritor continua a ameaçar o patrimônio cultural brasileiro. No entanto, a pesquisadora Angela Maria Fanini nos lembra que na obra poética de Mário de Andrade, "[...] em inúmeras vezes, há um deslumbramento com o progresso técnico, incluindo vários artefatos tecnológicos" (FANINI, 2010, p. 103).

Nesse sentido, Prysthon ressalta que o exercício de construção do moderno no Brasil se caracteriza pela "[...] utilização simultânea do novo e do arcaico, do futuro (e da ruptura com o passado) e do reaproveitamento do passado" (PRYSTHON, 2002, p. 148). Deslumbra-se assim, novos olhares sobre processos de digitalização que singularizam e constituem temáticas sobre a preservação de bens culturais na contemporaneidade. A pergunta que surge é 
como a tecnologia pode contribuir com a preservação de saberes e práticas tradicionais de uma determinada comunidade?

A resposta nos faz retornar ao começo do século XX para constatar que a preocupação com o patrimônio cultural brasileiro sempre esteve em debate. Desse modo, o artigo considera espaço ideal colocar em evidência a digitalização de materiais sobre patrimônios culturais e sua contribuição para a preservação e a disseminação de memórias históricas, visuais e sonoras, presentes em saberes e fazeres de uma comunidade.

O filósofo francês Paul Ricoeur nos lembra da importância da memória como grandeza cognitiva e indica o dever da memória e o lugar do presente para salvaguardar o passado (RICOEUR, 2003). Já Winer e Rocha, ao falar da Europeana, um dos projetos de digitalização mais importantes da Europa e que disponibilizou em 2008, o patrimônio cultural e científico de 27 Estadosmembros europeus, destacam que:

[...] documentos antes restritos à pesquisa física, que exigiam altos custos de deslocamento e estadia dos pesquisadores, se encontram agora na tela de seus computadores, enriquecendo e ampliando as fontes de suas pesquisas e a abrangência de suas abordagens. (WINER; ROCHA, 2013, p. 123)

Destarte, aspira-se que este estudo possa subsidiar novas indagações sobre a digitalização do patrimônio cultural brasileiro. Entende-se que as potencialidades do ciberespaço possibilitam novas metodologias preservacionistas, além de ampliar a interlocução com comunidades detentoras de saberes tradicionais. Logo, o reconhecimento do patrimônio cultural na atualidade é um ponto de partida para compreender a importância dos seus significados “[...] nos processos de construção de identidades, que são subjacentes à formação de hegemonias e culturas nacionais, à construção de nações e, sobretudo, do pertencimento" (ARANTES, 2010, p. 53).

Portanto, conclui-se que a digitalização torna-se um repositório capaz de conservar e difundir os valores culturais de um patrimônio imaterial. Conforme destaca Ricoeur, é preciso esforços para constituir a memória não apenas como uma matriz da história, mas como uma “[...] reapropriação do passado histórico por uma memória que a história instruiu" (RICOEUR, 2003, p. 6), um dever de 
memória que se refere a uma reinvindicação, um “[...] dever de fazer memória [...] o dever de não esquecer" (RICOEUR, 2003, p. 6). Neste sentido, o digital do imaterial abre-se como uma possibilidade para ampliar as metodologias de preservação e conservação de bens culturais, uma significativa contribuição para o registro de memórias e a formação de identidades. O digital do imaterial é o dever do presente com o passado, o dever do hoje com o amanhã.

\section{Referências}

ANDRADE, Mário de. Os cocos. São Paulo, Brasília: Duas Cidades/INL, 1984.

ANDRADE, Carlos Drummond de. Carlos e Mário: Correspondência de Carlos Drummond de Andrade e Mário de Andrade. Rio de Janeiro: Editora Bem-Te-Vi, 2003.

ANDRADE, Mário de. A situação etnográfica do Brasil. Jornal Síntese, Belo Horizonte, n. 01, ano 01, out. 1936.

ARANTES, Antonio Augusto. A salvaguarda do patrimônio cultural imaterial no Brasil. In: BARRIO, Ángel Espina; MOTTA, Antonio; GOMES, Mário Hélio (orgs.). Inovação cultural, patrimônio e educação. Recife: Fundação Joaquim Nabuco, Massangana, 2010.

ARANTES, Antonio Augusto. O patrimônio imaterial e a sustentabilidade de sua salvaguarda. Resgate, Campinas, v. 13, p. 11-18, 2004.

BRASIL. Constituição da República Federativa do Brasil. Brasília, DF: Senado Federal: Centro Gráfico, 1988.

AZEVEDO, José Eduardo. Apresentação. In: BOLSONI, Miriam (org.). Acervo de pesquisas folclóricas de Mário de Andrade: 1935-1938. São Paulo: Centro Cultural São Paulo (CCSP), 2000.

BOLSONI, Miriam (org.). Acervo de pesquisas folclóricas de Mário de Andrade: 1935-1938. São Paulo: Centro Cultural São Paulo (CCSP), 2000.

BRASIL. Decreto $\mathbf{n}^{0}$. 3.551, de 04 de agosto de 2000. Política de Salvaguarda do Patrimônio Cultural Imaterial. Brasília, DF.

CARLINI, Álvaro. Cachimbo e maracá: o catimbó da Missão (1938). São Paulo: Centro Cultural São Paulo, 1993. 
CARSALADE, Flávio. Bem. In: REZENDE, Maria Beatriz; GRIECO, Bettina; TEIXEIRA, Luciano; THOMPSON, Analucia (orgs.). Dicionário Iphan de Patrimônio Cultural. Rio de Janeiro; Brasília: Iphan/DAF/Copedoc, 2016.

CERQUEIRA, Vera Lúcia Cardim de; NASCIMENTO, Aurélio Eduardo do. Missão de Pesquisas Folclóricas: cadernetas de campo (DVD). Centro Cultural São Paulo, 2010.

CERQUEIRA, Vera Lúcia Cardim de. De Mário de Andrade ao Pavilhão das Culturas Brasileiras: mudanças das práticas institucionais de guarda da cultura popular. (Tese de Doutoramento apresentada ao Programa de Pós-Graduação Ciências Sociais) - Pontifícia Universidade Católica de São Paulo, São Paulo, 2016.

ESCOBAR, Herton. Incêndio no Museu Nacional reforça necessidade de digitalizar acervos. O Estado de S. Paulo, São Paulo, 2018, Geral.

FANINI, Angela Maria Rubel. Representações da tecnologia em alguns poemas da literatura brasileira. Anuário de Literatura, Florianópolis, v. 15, n. 01, 2010.

FRANCO, José Luiz de Andrade. Patrimônio Cultural e Natural, direitos humanos e direitos da natureza. In: SOARES, Inês Virgínia Prado; CUREAU, Sandra (orgs.). Bens Culturais e Direitos Humanos. São Paulo: Edições Sesc, 2015.

GIDDENS, Anthony; PIERSON, Christopher. Conversas com Anthony Giddens: o sentido da modernidade. Rio de Janeiro: FGV, 2000.

GONSALES, Patrícia Cecilia. A missão de pesquisas folclóricas realizada pelo departamento de Cultura de São Paulo na gestão de Mário de Andrade (19341938) e sua contribuição para a cultura popular. Revista Nacional de Gerenciamento de Cidades, Tupã, v. 01, n. 07, p. 54-67, 2013.

GUEDES, Maria Tarcila Ferreira; MAIO, Luciana Mourão. Bem cultural. In: GRIECO, Bettina; TEIXEIRA, Luciano; THOMPSON, Analucia (orgs.).

Dicionário IPHAN de Patrimônio Cultural. 2. ed. Rio de Janeiro, Brasília: IPHAN/DAF/Copedoc, 2016.

GUIMARÃES, Luiza Angélica Paschoeto. Memória, Educação e Folclore: o pensamento de professores e folcloristas ao movimento folclórico brasileiro da década de 1950. Revista Episteme Transversalis, Volta Redonda, v. 02, n.01, 2012.

IPHAN, Instituto do Patrimônio Histórico e Artístico Nacional. Programa Nacional do Patrimônio Imaterial (PNPI). Brasília, 2000. 
LEMOS JR, Urbano; GOSCIOLA, Vicente. Limites e possibilidades na preservação do patrimônio cultural brasileiro: uma conversa com Kátia Bogéa, presidente do Iphan. Revista Arqueologia Pública, Campinas, v. 12, n. 03, 2018.

LIRA, José Tavares Correia de. Naufrágio e Galanteio: viagem, cultura e cidades em Mário de Andrade e Gilberto Freyre. Revista Brasileira de Ciências Sociais, São Paulo, v. 20, n. 57, 2005.

LUCA, Tania Regina de. A Revista do Brasil: um diagnóstico para a (N)ação. São Paulo: Unesp, 1999.

LUVIZOTTO, Caroline Kraus. As tradições gaúchas e sua racionalização na modernidade tardia. São Paulo: Unesp, 2010.

LUVIZOTTO, Caroline Kraus A racionalização das tradições na modernidade: o diálogo entre Anthony Giddens e Jürgen Habermas. Revista Trans/Form/Ação, Marília, v. 36, p. 245-258, 2013.

LUVIZOTTO, Caroline Kraus. A disseminação da tradição e a preservação da memória coletiva na era digital. Liinc em Revista, Rio de Janeiro, v. 11, n. 1, p. 14-27, 2015.

MAGALHÃES, Aline Montenegro. Ouro Preto entre antigos e modernos: a disputa em torno do Patrimônio Histórico e Artístico Nacional durante as décadas de 1930 e 1940. Anais do Museu Histórico Nacional, Rio de Janeiro, v. 33, p. 190-208, 2001.

NATAL, Caion Meneguello. Mário de Andrade em Minas Gerais: em busca das origens históricas e artísticas do Brasil. Revista História Social, Campinas, n. 13, p. 197-207, 2007.

NATAL, Caion Meneguello. A vanguarda tropical de Mário de Andrade. Anais do Museu Paulista, São Paulo, v. 24, n. 02, p. 161-18, 2016.

NOGUEIRA, Antonio Gilberto Ramos. Inventário e Patrimônio Cultural no Brasil. História, São Paulo, v. 26, n. 02, p. 257-268, 2007.

OLIVEIRA, Pedro Rocha de. Viagem Etnográfica"ao Nordeste do Brasil: a crítica cultural de Mário de Andrade. Imburana Revista do Núcleo Câmara Cascudo de Estudos Norte-RioGrandenses, Natal, n. 04, jul./dez. 2011.

PELEGRINI, Sandra. O patrimônio cultural no discurso e na lei: trajetórias do debate sobre a preservação no Brasil. Patrimônio e Memória, Assis, v. 02, n.02, p. 54-77, 2006. 
PINHEIRO, Maria Lucia Bressan. Trajetória das ideias preservacionistas no Brasil: as décadas de 1920 e 1930. Revista do Patrimônio Histórico e Artístico Nacional, Brasília, n. 35, p. 13-32, 2017.

PINTO, Álvaro Vieira. Teoria da Cultura. Ciência e Existência: problemas filosóficos da pesquisa científica. Rio de Janeiro: Paz e Terra, 1969.

PRYSTHON, Ângela. Distintos cosmopolitismos: Mário de Andrade e Oswald de Andrade. Revista Gragoatá, Niterói, n. 12, 2002.

RICOEUR, Paul. Memória, história, esquecimento. Palestra proferida na Conferência Internacional Haunting Memories? History in Europe after Authoritarianism; Budapeste, 2003.

SANDRONI, Carlos. Missão de Pesquisas Folclóricas: Música Tradicional do Norte e Nordeste, 1938. Revista do Instituto de Estudos Brasileiros, São Paulo, n. 46, fev. 2008.

TONI, Flávia Camargo. O Pensamento Musical de Mário de Andrade. (Tese) Programa de Pós-Graduação em Artes da Escola de Comunicações e Artes, Universidade de São Paulo, São Paulo, 1990.

TONI, Flávia Camargo. Missão: as pesquisas folclóricas. Revista Usp, São Paulo, n.77, p. 24-33, mar./maio 2008.

WINER, Dov; ROCHA, Ivan Esperança. Europeana: um projeto de digitalização e democratização do patrimônio cultural europeu. Revista Patrimônio e Memória, Campinas, v. 09, n. 01, 2013.

\title{
Memory, identity and digitization of cultural heritage: the legacy of the Folkloric Research Mission in Brazil
}

\begin{abstract}
The article recoves an unprecedented and visionary initiative. In 1938, Mário de Andrade notes the need to register popular cultural events at the risk of disappearing with the country's growing urbanization and sends a team to the North and Northeast of Brazil for the Folk Research Mission. The group brings together a legacy through sound and audiovisual records. After more than sixty years, the material was digitized and today it is one of the most important Brazilian cultural records. The study points out this diligence as a precursor in search of a preservationist conscience on Brazilian soil, since it advocates the importance of registering materials on cultural heritage and its enormous relevance for the preservation of memories and identities. In this way, the objective of the article is to highlight the new procedures for the conservation,
\end{abstract}


dissemination and diffusion of cultural heritage in contemporary times. The methodology used is to analyze both the formatting of a physical product with digitized materials, and the development of a web platform with significant possibilities for the preservation and diffusion of cultural heritage. The study uses the theory of late modernity to talk about the continuity of traditions that are reincorporated and reinvented in cyberspace. The research results seek to broaden the debate about the importance of digitizing documents on cultural heritage and their consequent preservation. It is concluded, therefore, that digitalization can become a repository capable of conserving and disseminating the cultural values of a heritage, contributing to the preservation of memories and the formation of identities.

Keywords: Patrimony. Scanning. Memory. Cultural Identity. Folk Research Mission.

Recebido: $29 / 07 / 2020$

Aceito: $23 / 09 / 2020$

\section{Declaração de autoria}

Concepção e elaboração do estudo: Urbano Lemos Jr., Vicente Gosciola

Coleta de dados: Urbano Lemos Jr., Vicente Gosciola

Análise e discussão de dados: Urbano Lemos Jr., Vicente Gosciola

Redação e revisão do manuscrito: Urbano Lemos Jr., Vicente Gosciola

\section{Como citar}

LEMOS JR., Urbano; GOSCIOLA, Vicente. Memória, identidade e digitalização de bens culturais: o legado da Missão de Pesquisas Folclóricas no Brasil. Em Questão, Porto Alegre, v. 26, p. 181-205, Edição Especial Dossiê Patrimônio e Culturas Tradicionais, 2020. DOI: http://dx.doi.org/10.19132/1808-5245260.181-205

\footnotetext{
${ }^{1}$ FONSECA, Maria Cecília Londres da. O patrimônio em processo. Trajetória da política de preservação no Brasil: Rio de Janeiro, UFRJ, Iphan, 1997.

${ }^{2}$ LIMA, Alceu Amoroso. Pelo Passado Nacional. Revista do Brasil, volume 3, no 9, p. 14, set. 1916.

${ }^{3}$ O estudo foi publicado como crônica na Revista do Brasil, volume 14, no 54, do ano de 1920.

${ }^{4}$ ANDRADE, Mário de. A arte religiosa no Brasil. São Paulo: Experimento/Giordano, 1993. Apud Natal (2007).

${ }^{5}$ O marco do movimento modernista foi a realização da Semana de Arte Moderna (1922). O movimento reuniu escritores, poetas e artistas, como, Oswald de Andrade, Anita Malfatti, Graça Aranha, Ronald de Carvalho, Guilherme de Almeida, Victor Brecheret, Paulo Prado, Di
} 
Cavalcanti, Tarsila do Amaral, Manuel Bandeira, Mário de Andrade, entre outros. Os dois últimos tiveram importante papel na preservação do patrimônio cultural. Segundo o portal do Iphan, foi durante a Semana de Arte Moderna que Mário de Andrade se manifestou pela primeira vez acerca da dimensão imaterial do patrimônio.

Carta datada de 1 nov.1928 e remetida de Belo Horizonte. Documento preservado pelo Arquivo-Museu de Literatura Brasileira.

${ }^{7}$ A plataforma Caderneta Missão foi lançada em 2011 com a finalidade de difundir por meio online trabalhos documentais utilizados em consulta local, transcrições de cadernetas, materiais audiovisuais, anotações de campo, entre outros. A página da internet está disponível em: http://www.centrocultural.sp.gov.br/caderneta_missao.

${ }^{8}$ Kátia Bogéa está há mais de 30 anos na instituição, atuando na Superintendência do Instituto no Maranhão. A historiadora assumiu a presidência do Iphan em junho de 2016, permanecendo no cargo até dezembro de 2019. Atualmente, a presidente interina do instituto é a turismóloga Larissa Peixoto.

9 O Programa Nacional de Patrimônio Imaterial (PNPI) está disponível em: http://portal.iphan.gov.br/bcrE/pages/folPnpiE.jsf e traz informações sobre patrimônios registrados e instrumentos para salvaguarda.

${ }^{10}$ ANDRADE, Mário de. A situação Etnográfica do Brasil, Jornal Síntese, Belo Horizonte, n. 1, out. 1936. 